\title{
Die konsep, rituele en proses van Afrika-huwelike
}

M J Masango

(Universiteit van Pretoria)

\section{ABSTRACT}

\section{The concept, ritual and process of African marriages}

In many African tribes, sexual relations are legitimate only within the context of marriage. Moreover, all marriages are preceded by extensive preparations involving, inter alia, education (given by the elders of the community) and various religious rites de passage, e.g. circumcision. Boys and girls undergo separate initiations and several types of marriage (monogamy, polygamy, exogamy) prevail within traditional cultures. In this article, the author discusses elements of the variety of betrothal rites prevalent among African tribes as well as a number of global challenges affecting African marriage customs which have managed to hold their own despite the onslaught of westernisation and (post-) modernity.

\section{INLEIDING}

Webster's New Collegiate Dictionary (Webster 1981:698) gee die volgende definisie vir die woord 'huwelik':

The state of being married, the mutual relations of husband and wife or institution whereby men and women are joined in a special kind of social and legal dependence for the purpose of founding and maintaining a family. Finally, it is an act of marrying or the rite by which the married status is effected.

Aan die ander kant sien Mbigi \& Maree (1995:173) die huwelik as 'n sisteem:

It can be viewed as an arrangement which enables people to live together and co-operate with one another in an orderly social life. Bogenoemde aanhalings gee verskillende perspektiewe op die beheer wat mense se kultuur uitoefen op die maniere waarop hulle met ander in verhouding staan. In 'n Afrika-konteks word die proses beskou as die bymekaarkom van twee mense ('n paartjie) wat deur die huwelik aan die groep, familie of stam verbind word. Hierdie konteks beskou die huwelik dus nie as twee individuele wat hulle aan mekaar verbind nie, maar eerder as die bymekaarvoeg van twee individue, twee families, twee groepe of stamme en twee statte. Binne die westerse wêreld kan hierdie verstaan van huwelik maklik 
gesien word as ' $\mathrm{n}$ familiesisteem waardeur die groep, familie of stam beheer oor die paartjie wil uitoefen.

Aan beide kante van die spektrum bestaan daar sekere rituele waarby gehou moet word vir die huwelik om voltrek te word. Die insig van Brown en Forde (1987:3) verdien om genoem te word:

This kind of understanding of a kinship system as a working system, linking human beings together in an orderly arrangement of interactions, by which particular customs are seen as functioning parts of the social machinery, is what is aimed at in a synchronic analytic study.

Dit moet altyd in gedagte gehou word dat Afrika-mense binne die familiesisteem funksioneer en met mekaar in relasie tree, 'n sisteem wat veral gevind word onder gemeenskappe wat hul lewensonderhoud in klein of groot groepe verkry. Dit is juis een van die belangrikste redes vir Afrika-mense om binne sisteme te opereer wat die groep of stam insluit. Op hierdie manier is die hele groep betrokke wanneer van die lede in die huwelik tree. 'n Verstaan van die sisteme wat binne hierdie struktuur funksioneer word dus die voorwaarde vir die verstaan van Afrika-huwelike.

As voorbeeld kan Magesa (1997:49) se perspektief op die manier waarop mans in die plattelandse dorp of stat gewaardeer word, dien, ten einde 'n relasiewyse binne 'n Afrika-stat te illustreer:

Most men who live to maturity belong to two elementary families, i.e. to one as a son and brother and to the other as husband and father.

Dit is hierdie eenvoudige beginsel wat aanleiding gee tot ' $n$ hele netwerk van relasies of verhoudings wat die individu aan die vele ander lede van die groep verbind. Hierdie prinsiep is duidelik sigbaar in die proses of ritueel wat in voorbereiding vir die huwelik uitgevoer word. Soos Donkor (1997:8) oor hierdie verhouding verduidelik:

The individual is not only a physical being, but a spiritual and divine individual, who is compelled to live with other human beings.

Binne die Afrika-konteks word die lewe van ' $n$ individu dus in geheel binne die stat en in verbintenis met ander mense ondersoek, en hierdie familie-, groep- of stamsisteem moet in gedagte gehou word wanneer Afrika-huwelike ondersoek word. Kortom moet die 
Afrika-beskouing van die lewensproses, huwelik en rites, binne die perspektief van die sisteem- of groepkonteks geanaliseer word, aangesien Afrika-mense se funksionering binne so ' $n$ inklusiewe struktuur plaasvind. Met bogenoemde in gedagte, kan ons nou die Afrika-huwelik analiseer.

\section{AFRIKA-HUWELIKE}

Die instelling wat bestaan uit die kultureel aanvaarbare verbinding van twee mense in ' $n$ man-vrou verhouding, wat erkenning verleen aan rolle wat ' $n$ orde van seksuele gedrag daarstel en wat die funksie van ouerskap legitimeer, is 'n sentrale eienskap van alle menslike samelewings. Die skrywer is bewus daarvan dat die meeste moderne definisies tot ' $n$ dinamiese beskywing van die huwelik as proses (Phillips 1953:82) of as kameraadskap (Mair 1969:39) neig.

Mense tree weens ' $n$ groot verskeidenheid redes, wat oor ' $n$ wye spektrum strek, in die huwelik. In 'n stabiele, rationele stat of gemeenskap, word die huwelik geag weens die orde wat dit aan verhoudings verleen. Dit is deur hierdie orde wat eiendom toegeken word en aan erfgename oorgedra word. Sommige stamme sal byvoorbeeld vir ' $n$ jong paartjie twee of drie koeie gee om hulle nuwe lewe as getroude egpaar saam te begin (Schapera 1940:70). Die huwelik definieer die intieme kameraadskap tussen ' $n$ man en vrou. Dit voorsien vir en beskerm die nageslag en organiseer families.

Verskillende soorte huwelike word onder Afrika-mense aangetref, byvoorbeeld monogamie, poligamie, eksogamie ensovoorts, waaruit ek graag op die sogenaamde universele vorm van die huwelik, monogamie wil fokus. Hierdie soort huwelike het seksuele konotasies binne die stat. So byvoorbeeld word die koning toegelaat om baie vroue te trou vanwee sy status in die gemeenskap.

Monogamie was deur die loop van die geskiedenis, soos ook huidiglik, die mees algemene huwelikstipe om onder die samelewings van die wêreld voor te kom. Hierdie lank-gevestigde huwelikspatroon - een man en een vrou aan mekaar - het ten spyte van die skynbaar eindelose variasies en oortredings van die konvensionele, die model geword waarteen ander vorme geoordeel en aangepas word. In ouer, tradisionele statte, is hierdie huwelikstipe beskou as een wat vir arm mans bedoel is en wat gevolglik nie lobola kon bekostig nie. Mans wat dus met verloop van tyd ryker geword het, kon met twee of drie vroue trou, ' $n$ huwelikstipe wat as poligamie 
bekend staan, en wat gekoppel was aan die gebruiklike huwelik. Mair (1969:ix) wat hierdie huwelikstipe ondersoek het, deel 'n paar belangrike idees:

Another outstanding feature of African customary marriage is the institution commonly called 'bride-price' - commonly found in most African tribes... The making of payment of goods or services by the bridegroom to the bride's kin is an essential part of the establishment of legality.

Ongelukkig deel Mair nie die volle waarheid rondom hierdie proses van die huwelik nie, en ook nie rondom al die Afrika-huwelikstipes nie (monogamie, poligamie, eksogamie). Die eerste probleem met sy analise is die konsep van 'bruidsprys', wat onder Afrika-mense eerder 'lobola' genoem word, en wat die proses waardeur die twee families deur die huwelik een familie word, aandui. Tog word die huwelik nie voltrek deur die lobola nie, of totdat sekere rituele deur albei families uitgevoer is nie (hierdie konsep sal later verder ondersoek word).

Verder word elke familie deur twee persone van daardie familie verteenwoordig by die onderhandelinge van die proses, byvoorbeeld deur ooms en tannies, of maditsela, soos dit algemeen onder die Tswanas bekend staan. Terwyl die onderhandelinge voortduur, kry die families die geleentheid om mekaar beter te leer ken, en stel dit hulle in staat om die paartjie vir die huwelik voor te berei.

Derdens, nadat lobola en die ander goedere aan die bruid se huis gegee is, moet die bruid se familie ' $n$ skaap slag as deel van die proses wat die ritueel van die Afrika-huwelik voltooi. Die slagting verteenwoordig die einde van die onderhandelinge, en die huwelik self sal later gewettig word. Die bruidsprys (volgens Mair) of die lobola (volgens Afrika-mense) dien dus om die nuwe familiebande te smee en uit te druk. In die woorde van Onwuejeogwu (1975:63):

When lobola is completed by the groom's family, the two families by giving and accepting it, have created a new pattern of relationships, and behaviour fully expressed in the avoidance rule.

Die paartjie word nou toegelaat om seksuele omgang te geniet binne die verhouding. Sou hierdie omgangs ritueel nie uitgevoer of voltooi word nie, is die huwelik nie voltrek nie. Magesa (1979:126) merk op dat 'in reality, this is still courtship, a sexual relationship is not allowed. It has not yet become a marriage'. Dus sou die bruid se pa 
weier om sy toestemming vir die huwelik te gee en die terugkeer van sy dogter vereis. Die situasie verander egter as hy die lobola aanvaar, en dan word ' $\mathrm{n}$ skaap vir die bruid se familie geslag. Uiteindelik sal hy ' $n$ bul ontvang (Tongas) as tussenbetaling, maar sal nie op enigiets anders aandring nie.

Nog ' $n$ perspektief wat deur westerse skrywers oor die hoof gesien word, is die uitruiling van geskenke deur beide families. Die Ndebele (Suid-Afrika) familie van die bruid staan onder verpligting om geskenke vir die pa, ma, susters, broers, ouma en oupa (van die vrou) te koop. Die rede vir so 'n oonskynlik gekompliseerde sisteem mag vir die westerling verrassend wees, maar dit vind plaas as ' $n$ manier om ' $n$ diep verhouding met die paartjie, familie, groep, stam en tussen die twee statte te bou. Sodoende, wanneer die paartjie later as egpaar saamleef, bestaan daar vir hulle ' $n$ ondersteuningsisteem wat aan hulle hulp kan verleen. As hulle byvoorbeeld huweliksprobleme sou ondervind, sal beide ooms en tannies moet bydra tot die oplossing van die probleem. Kortom wy die onderhandelaars (mma ditsela soos onder die Basuto bekend) hulself dus lewenslank toe aan die paartjie wanneer hulle tot die onderhandeling van die huweliksproses toetree.

Die ander huwelikstipes wat in plattelandse omgewings waargeneem is, is poligamie en eksogamie, ' $n$ huwelik wat ' $n$ man of vrou van buite die groep behels het. Hierdie huweliksoort is nie dikwels aangemoedig nie, en veral nie onder die ouer stamme van die verlede nie. Soos wat stamme gegroei het, het hulle hul seuns aangemoedig om binne die groep in die huwelik te tree. Buitestaanders moes deur ' $\mathrm{n}$ moeisame proses gaan ten einde onder die stam verwelkom te word, en die klem het dus geval op huwelike binne die grense van die betrokke stam. Wanneer eksogamie wel plaasgevind het, het dit bygedra om bloedskande te voorkom en die kontakte van 'n familielyn uit te brei, en sodoende ook die familie se eiendomsbesit. Die koninklike familie het oor hierdie huweliksgebruik toesig gehou, en hulle seuns en dogters is aangemoedig om binne ' $n$ bepaalde klas in die groep, of met iemand van ' $n$ hoë rang onder die inwoners van ' $n$ stat in die huwelik te tree. Kortom het hulle dus slegs met die adelikes van die ander groepe getrou. Die koninklike familie het dus streng reels aangaande die huwelik en seksuele verhoudings - geen persoon wat nie van die adelstand is word toegelaat om in die familie in te trou nie. 
Die volgende huwelikstipe onder landelike Afrika-groepe was poligamie, of die huwelik tussen een man en verskeie vroue. Hierdie huwelikstipe het deur eeue se gebruiksveranderinge heen oorleef, was baie algemeen in Afrika, en is nou verwant aan die bybelse literatuur, soos byvoorbeeld die huwelik van koning Salomo in (1 Konings). Seksuele probleme is deur beide families gehanteer. In die hede volg party stamme steeds hierdie patroon van ooreenkomste en relings.

Die rede vir die voorkoms van poligamie word nie altyd deur skrywers aangeraak nie. Poligamie was ' $n$ kultuurverskynsel, en veral wanneer ' $n$ vrou nie in staat was om kinders te hê nie. In so 'n geval sou die familie, insluitende die man se vrou, ooreenstem dat die man met ' $n$ suster of ander familielid van die vrou in die huwelik tree met die doel om kinders te verwek.

Soos vroeër genoem is, sou ryk mans met verskeie vroue trou, omdat hulle dit kon bekostig om vir hulle te sorg. Phillips (1953:xiv) noem dat 'having a number of wives is normally a mark of importance and success in life'. Hierdie verskynsel was afhanklik van die mag en invloed wat ' $n$ man in die stat gehad het, en hoe goed dit bestuur is. Koning Sobusua van Swaziland dien as 'n goeie voorbeeld. Sy struktuur het ook meer beskerming aan weduwees gebied, omdat dit verseker het dat vroue binne die geslagslyn sou bly na die dood van hul mans, en dat hulle materieel versorg sou wees. Njenga (1974:117) ontwikkel hierdie idee verder wanneer hy sê:

The husband sincerely felt that each of his wives had a unique relationship with him, a relationship that was of husband and wife... [This] conjugal relationship was in a manner analogous to friendship, viewed as capable of being realized among various persons (wives) and not exclusively lied up with one person (wife).

Huwelike in 'n Afrika-stat is deur ouer mense oorsien en gerig, en is in die sorg van die inwoners gelaat. Elkeen was betrokke in die opbou van die groep, en die verantwoordelikheid van die huwelik was geleë binne die familiebande, gemeenskap en die man. Olupona (1991:69) deel 'n belangrike opmerking rondom 'n man met baie vroue:

Morally, the responsibility of the husband to all the wives and children in a polygamous marriage is the same. What he requires 
to do to one in terms of affection and concern, sexually, he is morally bound to do to all.

As dit vir die man nie moontlik sou wees om by hierdie morele standaard te hou nie, sou dit vir hom oneties wees om tot ' $\mathrm{n}$ poligame huwelik toe te tree, en sou hy die risiko van openbare spot en sensuur loop vir die vernietiging van die betrokke partye se lewenskwaliteit. Belangrik om raak te sien is dat hierdie huwelikstipe ook aan verantwoordelikhede verbind moet word, veral sover dit getroude vroue aangaan, en ten einde 'n goeie voorbeeld vir die ander inwoners te stel.

Albei hierdie huwelikstipes het onder Afrika-mense voorgekom, maar ekonomiese en opvoedkundige veranderinge, asook die opheffing van vroue deur modernisering, het gelei tot verskeie uitdagings van poligamie. Alhoewel dit steeds op ' $\mathrm{n}$ klein skaal in landelike gebiede voorkom, moet die volgende vraag gevra word: wanneer is ' $n$ huwelik ' $n$ huwelik? Die skrywer het verwys na die gebruik van lobola, en dat dit belangrik is om hierdie stap of ritueel wat tot die huwelik lei, te verstaan. Die oorblywende deel van die opstel sal nou die proses van lobola ondersoek, asook hoe dit in die praktyk van verskillende stamme funksioneer. Ten einde reg aan die onderwerp van bespreking te laat geskied, moet die proses van lobola verstaanbaar gemaak word.

\section{DIE RITUEEL VAN LOBOLA}

Die onderhandelingsproses in voorbereiding van die huwelik verskil van stam tot stam. Onder die Zandes (Ghana), byvoorbeeld, word lobola oor ' $\mathrm{n}$ lang tydperk betaal, na die aanvanklike oorhandiging van die simboliese vee (Mngomezulu 2001:14). Die res van die vee word met die geboorte van dogters oorhandig, sodat dit in werklikheid in die Zande-sisteem hierdie kinders is wat die bruidskat (lobola) vir hul ma voorsien, net soos hul eie dogters ook onder ideale toestande vir hulle sal doen. Die ekonomiese belang van lobola word dus grootliks oorskadu deur die verenigende, sosiale krag en waarde daarvan. Die rede vir so ' $n$ langtermyn betaling van die lobola in plaas van 'n eenmalige oorhandiging, is dat die huwelik in die begin slegs as ' $n$ 'huwelik in embrio' beskou word. Namate die huwelik volwasse word, verkry die oorblywende gebruike tussen lede van ' $n$ huweliksgroep meer definisie. Die geboorte van ' $n$ kind bewerk verder ' $n$ ontspanning of beëindiging van die reël van vermyding, soos reeds uitgewys is, en die vrou word waarlik as deel 
van haar man se groep geïnkorporeer, soveel so dat sy 'vervang' moet word wanneer sy sterf. So sal die man weer binne dieselfde familie in die huwelik tree, in ' $n$ sogenaamde sororate eenheid. Die huwelik is oog verbind met seksuele verantwoordelikheid en die plig om die familie voort te plant. Eers na die geboorte van die kind word die vrou volkome binne die familie aanvaar.

Die Basotho's van Lesotho begin op hulle beurt met 'n proses van hofmakery, wat gevolg word deur die wegvoering van die bruid deur ' $n$ groep van die bruidegom se vriende, waarna die bruidegom se pa ' $n$ boodskapper na die bruid se familie stuur met die woorde batlelang kwano, 'probeer om haar by ons huis te vind'. Op hierdie manier word daar dan begin met die huweliksonderhandelinge, alhoewel die huwelik self nog nie begin het nie en al die gebeure steeds deel van die hofmakery uitmaak. Wanneer die boodskappers terugkeer, word verskeie rituele by beide die bruid en die bruidegom se families uitgevoer. Teen hierdie tyd het die bruid al begin terugkeer na haar ouerhuis, waar sy sal aanbly totdat die onderhandelingsproses afgehandel is, lobola en alle komberse, ensovoorts betaal is. Later sal die bruid weer na die bruidegom se huis geneem word, hetsy deur boodskappers of deur ooms of tannies, en dit is op hierdie stadium dat die huwelik begin het. Na die feesvieringe by die famlilie word die paartjie toegelaat rites in die rite wat deur die oudstes van die stat uitgevoer word.

$\mathrm{Na}$ ' $\mathrm{n}$ tydperk van drie maande sal die nuwe stam die bruid toelaat om haar ouerhuis te besoek, ten einde haar proses van in die huwelik tree af te handel. Die laaste ritueel word uitgevoer met die doel om aan haar die toestemming te verleen om vir haar man te kook. Wanneer sy na drie maande terugkeer na haar nuwe stam, ontvang sy ' $n$ aantal huishoudingsartikels, die teken dat sy nou gereed is om outoriteit oor haar eie huis te neem. Die hofmakery is nou geheel en al verby, en die getroude lewe het begin. Tog is die huwelik nie ten volle voltrek voor die geboorte van 'n kind nie. Nadat ' $n$ kind, verkieslik eerste ' $n$ seun, gebore is, behoort die huwelik nie onder enige omstandighede verbreek te word nie: die huwelik se eise bly tot selfs na die dood bindend. Die Kikuyu, Luo en tradisioneel landelike Zoeloes bewys steeds eer aan hierdie proses. As die vrou sou doodgaan, word die man na ses maande toegelaat om met die bruid se suster te trou. As dit die man is wat sterf, moet een van sy broers of ander familielede met die weduwee 
in die huwelik te tree ten einde sy kinders namens hom groot te maak (Pritchard 1970:241-242).

Kortom is dit dus belangrik om raak te sien dat die voltrekking van die huwelik onder die Basotho's, Luo's en Kikuyu's deur die geboorte van 'n kind plaasvind. Van hierdie punt af behoort die man en vrou geheel en al aan mekaar, en die band tussen twee families en gemeenskappe is geseël. Hierdeur word 'n nuwe status en gesag aan die vrou verleen, en sy word nou ten volle as deel van die familie, stam of groep aanvaar. Shorter (1974:183) noem dat

The couple's lives are qualitatively more complete: they have fulfilled the most basic responsibility of their existence as human beings, to themselves and to their communities, by becoming parents.

Alhoewel globalisasie ' $\mathrm{n}$ uitdaging aan hierdie proses gestel het, geld die beginsel van lobola selfs vandag nog as die begin van die onderhandelingsproses.

\section{GEVOLGTREKKING}

Die prentjie wat hierbo oor Afrika-huwelike geskets is, beteken nie dat die outeur onbewus is van ineenstortings in die sisteem van Afrika-huwelike weens die veranderinge wat in die groter konteks van die wêreld plaasvind nie. So is daar byvoorbeeld sedert die einde van die tweede wêreldoorlog merkwaardige uitdagings aan Afrikahuwelike gestel. Globalisasie het ook bygedra om Afrika-huwelike tot verandering te dwing weens ekonomiese druk. Die druk wat deur hierdie veranderinge in die samelewing uitgeoefen word, word nou deur families ervaar. Jongmense verlaat landelike gebiede op soek na groener weivelde, met die gevolg dat daar 'n verbrokkeling van gesinstrukture plaasvind. In Suid-Afrika is hierdie impak veral ervaar as gevolg van die trekarbeidersisteem, wat mense met dwang verwyder en verdeel het. Dus het die familie- en stamsisteem van alle kante ongelooflike druk ervaar, en moet die Afrika-familie nou noodgedwonge by hierdie ingrypende veranderinge aanpas.

Lobola is een van die gebruike of rituele wat steeds standhou binne die Afrika-huwelik, waar dit funksioneer as ' $n$ fondasie vir die tot stand bring daarvan. ' $n$ Interessante verandering of aanpassing binne Afrika-huwelike is dat sommige jong paartjies hulle tot terapie wend wanneer daar probleme sou opduik. Merkwaardig genoeg keer hulle wel terug na die tradisionele Afrika-manier van probleemhantering in gevalle waar terapie nie werk nie. Hierdie verskynsel 
kom veral voor onder jongmense wat in stedelike gebiede woon. Ander paartjies maak van die kerkstruktuur gebruik om hulle probleme aan te spreek.

Dit is belangrik om in gedagte te hou dat, nieteenstaande die veranderinge, die familie steeds die hartklop en kern van die Afrikagemeenskap is. Dit beteken dat die familie steeds die ordelike ontwikkelingbasis van die solidariteit van die familie-eenheid vorm, ook terwyl dit in die proses van aanpassing onder moderne omstandighede en voorwaardes is. Diegene wat in stedelike gebiede woon keer terug na die landelike gebiede met tye soos Paasfees, Kersfees en ander belangrike vakansietye. Hiertydens kan die meeste van die probleme wat opgeduik het deur volwassenes, familielede, inwoners en stamhoofde hanteer en opgelos word.

Die outeur is verder bewus van die hoë egskeidingsyfer onder Afrika-huwelike. Paartjies probeer tussen Afrika- en westerse lewensstyle funksioneer en is vasgevang tussen die twee kulture en wêreldbeskouings. Hierdie aspek van Afrika-huwelike is opsigself vrugbare aarde vir verdere en voortgesette navorsing.

Bogenoemde en ander veranderinge in die samelewing het ook ' $n$ impak gemaak op Afrika-kinders, waarvan sommige ' $n$ westerse lewenswyse aangeneem het. Nieteenstaande die verspreiding van alternatiewe huwelikstipes en die groeiende verdraagsaamheid in hierdie verband, sal monogamie steeds die standaard bly waarteen alle ander vorme van huweliksverhoudings geëvalueer sal word. Dus sal die konvensionele verwagting van huwelike, soos huwelikstrou, kinderopvoeding en mutualiteit steeds voortbestaan. Selfs in die geval van korter kontrakte vir huwelike sal die ideaal van huwelikstabiliteit vir die meerderheid geldende outoriteit verkry, en as ' $n$ samelewingstandaard voortbestaan.

\section{Literatuurverwysings}

Brown, R \& Forde, D 1978. African systems of kinship and marriage. London: International African Institute.

Magesa, L 1997. African religion: The moral traditions of abundant life. Maryknoll: Orbi’s Books.

Mair, L 1969. African marriages and social change. London: Frank Cass Company.

Mbigi, L \& Maree, J 1995. Ubuntu: The spirit of African transformation management. Pretoria: Knowledge Resources. 
Mngomezulu, M W 2000. Ilobolo: A cybernetic description of marital relationship. Pretoria: University of Pretoria (PhD Dissertation).

Njenga, J 1974. Customary African marriages. London: SCM Press.

Olupono, J K 1991. African traditional religion in contemporary society. Minnesota: Paragon House.

Onwuejeogwu, M A 1975. The social anthropology of Africa: An introduction. London: Heinemann.

Phillips, A 1953. Survey of African marriages and family life. London: Oxford University Press.

Prichard, E 1970. The position of women in primitive societies. New York: Orbis Books.

Schapera, I 1940. Married life in an African tribe. Edinburgh: Edinburgh Press.

Shorter, A 1974. African culture and the Christian Church: An introduction to social and pastoral anthropology. New York: Orbis Books.

Webster, M 1981. Webster's new collogiate dictionary. Springfield: G \& C Merriam Company. 